\title{
Comparison of Persistence and Adherence Between Adults Diagnosed with Attention Deficit/ Hyperactivity Disorder in Childhood and Adulthood
}

\author{
Sang-Min Lee iD ' \\ Hyeon-Kyoung Cheong (iD ${ }^{2}$ \\ In-Hwan $\mathrm{Oh}^{3}$ \\ Minha Hong (iD) 4 \\ 'Department of Psychiatry, Kyung Hee \\ University School of Medicine, Seoul, \\ Korea; ${ }^{2}$ Department of Internal Medicine, \\ Korea University School of Medicine, \\ Ansan, Korea; ${ }^{3}$ Department of Preventive \\ Medicine, Kyung Hee University School \\ of Medicine, Seoul, Korea; ${ }^{4}$ Department \\ of Psychiatry, Myongji Hospital, Hanyang \\ University College of Medicine, Goyang, \\ Korea
}

Purpose: Long-term treatment of attention deficit/hyperactivity disorder (ADHD) is important, but adherence and persistence in practice are still suboptimal. To better understand medication compliance for ADHD, we divided adults with ADHD into groups based on their history of childhood and adolescent ADHD, and compared their characteristics, medication adherence and persistence, and associated factors.

Patients and Methods: This study included participants aged 18-23 years with claims related to ADHD (International Classifications of Diseases 10th edition, F90.0x) and antiADHD medication from July 1, 2017 to December 31, 2018, and with a history of any F90.0x claim(s) from January 1, 2007 to June 30, 2017 in the Korean National Health Insurance System Claims database. Participants were divided into those diagnosed with ADHD in childhood and adulthood. Persistence with or without a 30-day gap and adherence according to a medication possession ratio (MPR) $>80 \%$ were calculated.

Results: There were 10,604 patients included in the study. Adults with a childhood diagnosis of ADHD showed significant male predominance, more use of National Health Insurance, and were more often treated by psychiatrists and in hospitals than those with an adulthood diagnosis. Combination therapy was the most common initial treatment in those with an adulthood diagnosis, while monotherapy with Concerta was most common in those with a childhood diagnosis. Both groups had over $60 \%$ of participants with an MPR $>80 \%$ and over $50 \%$ with persistence without a 30-day gap. Treatment in a private clinic and initial monotherapy with bupropion were found to be significantly associated with adherence in both groups.

Conclusion: The significant differences found between these groups add evidence to suggest that adult with ADHD diagnosed in adulthood may be a separate entity from those in childhood. A thorough evaluation at diagnosis and treatment in private clinics may improve medication compliance in this population.

Keywords: adult ADHD, persistence, adherence, compliance

\section{Introduction}

Attention deficit/hyperactivity disorder (ADHD) is a prevalent psychiatric disorder among children and adolescents and often continues to adulthood with symptoms. Polanczyk et al reported the global prevalence of ADHD as about $5 \%$, ${ }^{1}$ and as $1.2 \%$ to $7.3 \%$ in adults specifically. ${ }^{2}$ Pharmacotherapy in adults with ADHD is cost-effective and is often recommended as a first-line treatment. ${ }^{3}$ It is a robust and safe method for the management of ADHD. ${ }^{4}$ In addition, long-term treatment of ADHD with medication results in better outcomes in academic and social function. ${ }^{5,6}$ For children and adolescents, Hong et al reported that medication compliance up to 36 months was only
Correspondence: Minha Hong Department of Psychiatry, Myongji Hospital, Hanyang University College of Medicine, 55 Hwasu-ro 14 beon-gil, Deogyang-gu, Goyang, 10475, Korea Tel +82-10-8433-0124

Fax +82-3I-969-0500

Email hmh0124@hanmail.net;

minhahong@hanyang.ac.kr 
approximately $20 \%{ }^{7,8}$ Medication compliance is suboptimal in adults, although it is higher than that in children and adolescents. Because of its chronic nature, long-term pharmacotherapy is needed, but compliance is low.

The Diagnostic and Statistical Manual of Mental Disorders (DSM) and the 10th edition of the International Classification of Diseases (ICD-10) differ in how they define ADHD. The ICD-10 system classifies ADHD as a category of "behavioral and emotional disorders with onset usually occurring in childhood and adolescence" rather than a category of neurodevelopmental disorder, usually diagnosed within the first five years of life. ${ }^{9}$ In addition, the same criteria are required in adults, such as children and adolescents. Meanwhile, the DSM diagnostic criteria for ADHD in adults require a history of childhood (before 12 years of age) symptoms. However, adult-onset ADHD without a childhood history has been reported. Moffitt et $\mathrm{al}^{10}$ and Agnew-Blais et al ${ }^{11}$ suggested the possibility of adult-onset ADHD. Cooper et al also found a case of adult-onset ADHD with typical childhood development and suggested that an unidentified form of ADHD might arise during adulthood. ${ }^{12}$ It is noteworthy that the parents of $78 \%$ of subjects with childhood ADHD had forgotten the age of ADHD onset before age 12 (even though they reported the symptoms at ages 5, 7, 9, and 11 years), and $4 \%$ of parents of 35 comparison subjects falsely recalled their child as having ADHD. ${ }^{10}$ Although ADHD is a neurodevelopmental disorder, there is still some debate over whether adult ADHD is childhood ADHD diagnosed later in life or is a type of ADHD that simply has a late onset. Considering the chronic condition of ADHD, it will be helpful to compare and analyze adults with ADHD with and without childhood history to further accumulate and improve the knowledge of compliance.
The aim of this study was to investigate and characterize compliance in adults with ADHD who were diagnosed in childhood and diagnosed in adulthood using national health insurance claims data.

\section{Materials and Methods Data Source and Study Population}

This was a retrospective study using data from the Korean National Health Insurance Service (NHIS) claims database. The diagnosis of ADHD was determined based on the presence of claims registered by the physician. An enrolment flowchart is shown in Figure 1. Cases aged 18-23 years with any ICD-10 F90.0x code and any antiADHD medication (Table 1) claim(s) between July 1, 2017 and December 31, 2018 were divided into groups according to the history of any F90.0x ICD-10 code claim(s) between January 1, 2007 to June 30, 2017 (Figure 1). Adults with a previous history of ICD-10 F90.0x claim(s) were considered to have been diagnosed with ADHD in childhood or adolescence (childhood group), while those without a previous history were considered to be newly diagnosed in adulthood (adulthood group). Medication use in adults with ADHD has been approved in Korea since June 2016. Data from the NHIS are available from January 1, 2007. Considering the period during which medication use in this population became popular for about one year, cases with the F90.0x code were targeted from July 1, 2017 to December 31, 2018. In particular, the age was confined to 18-23 years to define and compare the childhood and adulthood groups based on available data. This study was approved by the institutional review board of Myongji Hospital (MJH 2019-05-014).

Jul 1, 2017- Dec 31, 2018

(1) aged $18-23$ years

(2) at least one claim of ICD-10 F90.0x

(3) at least one claim of anti-ADHD medication

\section{[Childhood Dx Adult ADHD]}

Any ICD-10 F90.0x claim(s) between Jan 1, 2007-Jun 30, 2017

\section{[Adulthood Dx Adult ADHD]}

No ICD-10 F90.0x claim(s) between Jan 1, 2007-Jun 30, 2017

Figure I Flow of sample grouping.

Abbreviations: ADHD, attention deficit/hyperactivity disorder; Dx, diagnosis; ICD-10, International Classification of Diseases, I0th edition. 
Table I Characteristics of Adult Patients Diagnosed with Attention Deficit/Hyperactivity Disorder in Adulthood and Those Diagnosed in Childhood

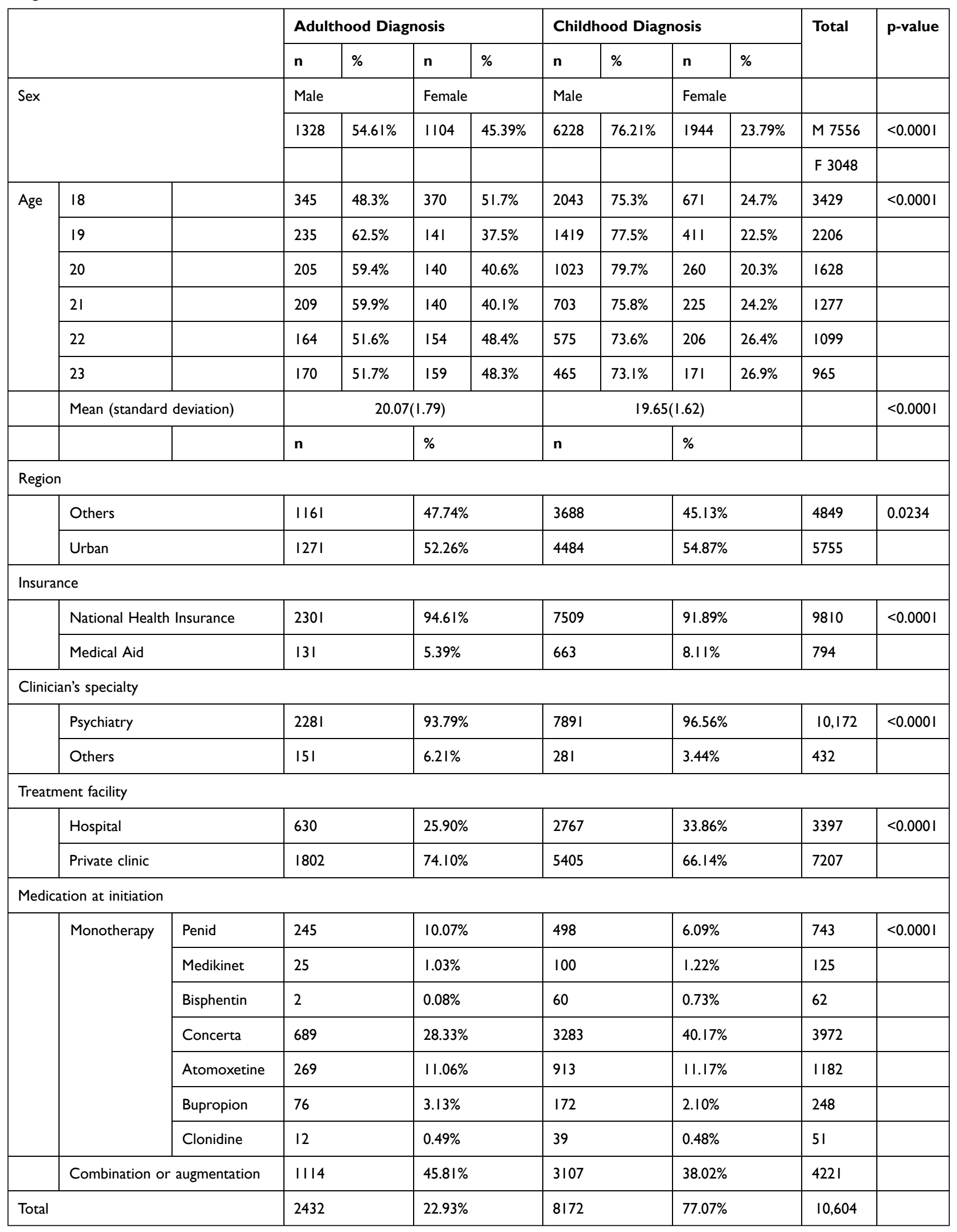




\section{Study Variables \\ Medication}

Methylphenidate (Penid, Medikinet, Concerta, Metadate $\mathrm{CD}$, Bisphentin), atomoxetine, bupropion, and clonidine are used to treat ADHD. While these 8 types of antiADHD medications are all available in Korea, Metadate $\mathrm{CD}$, Bisphentin, and clonidine are not approved for adults with ADHD in Korea.

\section{Persistence and Adherence}

Persistence was defined as the number of days of continuous therapy (without a 30-day gap) during the post-index period (from the index date to the last date of medication prescription). Adherence was calculated using the medication possession ratio (MPR). The MPR reflects the number of days for which patients were in possession of their prescribed medication. In this study, the MPR was calculated by summing the daily supply and dividing by the treatment period.

\section{Covariates}

Information regarding sociodemographic factors, such as age, sex, type of insurance, region of residence, and medical factors (including hospital level and clinician specialty), were obtained from the Health Insurance and Review Assessment (HIRA) database. The insurance types were classified into two categories: National Health Insurance (NHI) and Medical Aid. Clinicians' specialties were categorized as psychiatry and others (non-psychiatry). Hospitals were classified as either hospitals or clinics.

\section{Statistical Analysis}

Descriptive statistics and chi-squared tests were used to assess medication use and clinical and demographic variables. Student's $t$-tests were used to compare the adulthood and childhood groups. The chi-squared test and CochranMantel-Haenszel tests were used to assess persistence and adherence. To investigate the factors associated with adherence and persistence, multivariate logistic regression analysis was employed. SAS 9.3 (SAS Institute, Cary, NC) was used to analyze the data. An a priori significance level of $\mathrm{p}<0.05$ was used for all statistical analyses.

\section{Results}

\section{Group Characteristics}

Table 1 shows the demographic characteristics of the 10,604 study participants. After stratification, 8172 (77.06\%) were assigned to the childhood group and $2432(22.94 \%)$ to the adulthood group. The childhood group showed significant male predominance compared to the adulthood group $(\mathrm{p}<0.0001)$. Most participants in both groups lived in urban areas, with significantly more living in urban in the childhood group $(p=0.0234)$. Most participants in both groups used NHI for insurance, with significantly more using NHI in the adulthood group $(p<0.0001)$. Most adult ADHD cases were diagnosed by psychiatrists $(95.92 \%)$. The proportion of patients diagnosed by non-psychiatrists was significantly higher in the adulthood group than in the childhood group (6.21\% vs $3.44 \% ; \mathrm{p}<0.0001)$. Most adult ADHD patients were treated in private clinics $(67.96 \%)$, with significantly more patients in the adulthood group than in the childhood group $(p<0.0001)$. There were significant differences between groups in first prescribed anti-ADHD medications $(p<0.0001)$. Most participants in the childhood group were initially prescribed Concerta (40.17\%), followed by combination therapy (38.02\%), atomoxetine $(11.17 \%)$, Penid $(6.09 \%)$, bupropion $(2.10 \%)$, and

\section{Childhood Dx AA}

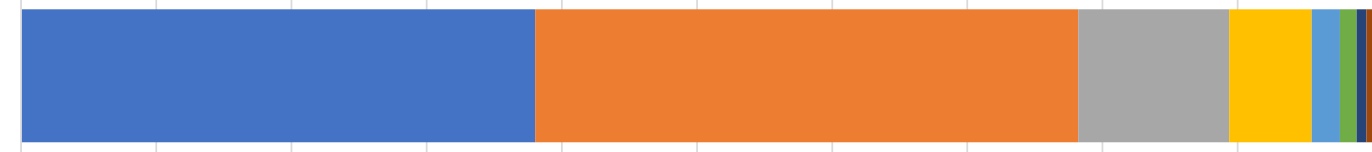

Adulthood Dx AA
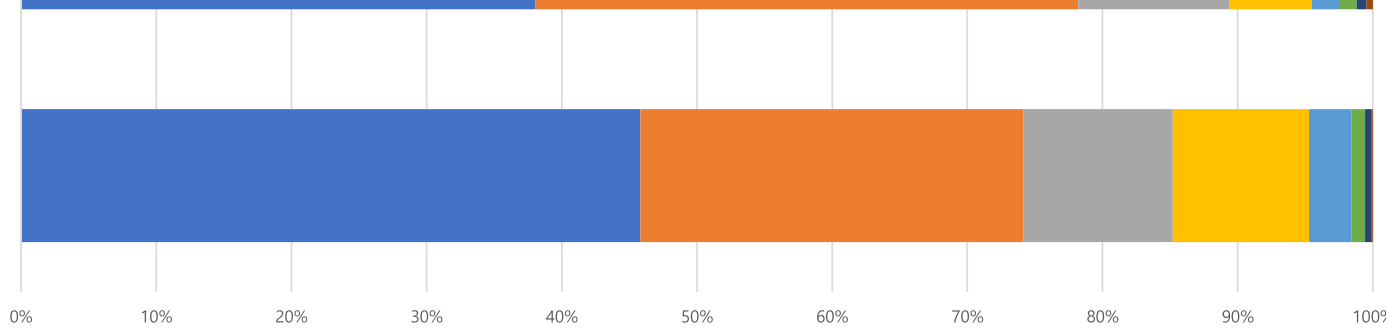

COMBI

- Conerta Atomoxetine Penid

$40 \%$

$50 \%$

$60 \%$

- Clonidine

Bisphentin

Figure 2 Anti-attention deficit/hyperactivity disorder medication at treatment initiation. 
Table 2 Medication Persistence in Adult Patients Diagnosed with Attention Deficit/Hyperactivity Disorder in Adulthood and Those Diagnosed in Childhood

\begin{tabular}{|c|c|c|c|c|c|c|c|c|c|}
\hline & & & \multicolumn{6}{|l|}{ Age } & \\
\hline & & & 18 & 19 & 20 & 21 & 22 & 23 & \\
\hline \multirow[t]{15}{*}{ Adulthood diagnosis } & \multirow[t]{5}{*}{ Total } & $\mathrm{N}$ & 251 & 133 & 131 & 136 & 126 & 124 & 901 \\
\hline & & Mean & 135.43 & 132.96 & 142.66 & 138.82 & 147.58 & 125.4 & 136.95 \\
\hline & & (SD) & 121.92 & 114.77 & 131.99 & 130.17 & 125.38 & 128.57 & 124.91 \\
\hline & & Median & 129 & 109 & 120 & 117 & 134 & 87.5 & 118 \\
\hline & & $(\mathrm{IQR})$ & $0-220$ & $50-217$ & $0-209$ & $0-196$ & $46-231$ & $0-202.5$ & $0-219$ \\
\hline & \multirow[t]{5}{*}{ Male } & $\mathrm{N}$ & 123 & 73 & 70 & 81 & 59 & 58 & 464 \\
\hline & & Mean & 138.95 & 141.64 & 138.76 & 142.15 & 150.73 & 111.72 & 138 \\
\hline & & (SD) & $126.9 \mid$ & 121.77 & 141.22 & 135.19 & 125.82 & 120.94 & 128.75 \\
\hline & & Median & 133 & 109 & 117 & 110 & 136 & 75.5 & 112 \\
\hline & & (IQR) & $0-224$ & $49-238$ & $0-204$ & $0-189$ & $50-248$ & $0-175$ & $0-219$ \\
\hline & \multirow[t]{5}{*}{ Female } & $\mathrm{N}$ & 128 & 60 & 61 & 55 & 67 & 66 & 437 \\
\hline & & Mean & 132.05 & 122.4 & 147.13 & 133.93 & $|44.8|$ & $|37.4|$ & 135.83 \\
\hline & & $(\mathrm{SD})$ & 117.32 & 105.66 & 121.56 & 123.46 & 125.88 & 134.69 & 120.85 \\
\hline & & Median & 119 & 110.5 & 129 & 121 & 131 & 110.5 & 119 \\
\hline & & $(\mathrm{IQR})$ & $0-210.5$ & $53-179.5$ & $5 I-24 I$ & $0-251$ & $0-225$ & $0-246$ & $0-212$ \\
\hline \multirow[t]{15}{*}{ Childhood diagnosis } & \multirow[t]{5}{*}{ Total } & $\mathrm{N}$ & 1055 & 797 & 579 & 411 & 347 & 262 & 3451 \\
\hline & & Mean & 201.53 & 219.75 & 209.93 & 202.07 & 200.25 & 193.49 & 206.47 \\
\hline & & (SD) & 124.96 & $|2| .2 \mid$ & 126.78 & 135.27 & $13 \mid .87$ & 127.1 & 126.74 \\
\hline & & Median & 188 & 219 & 196 & 184 & 189 & 187 & 196 \\
\hline & & $(\mathrm{IQR})$ & $105-273$ & $136-293$ & I I 2-287 & $104-275$ & $99-286$ & $96-282$ & $110-283$ \\
\hline & \multirow[t]{5}{*}{ Male } & $\mathrm{N}$ & 773 & 601 & 448 & 298 & 250 & 177 & 2547 \\
\hline & & Mean & 200.69 & 219.25 & 213.07 & 203.6 & 205.57 & 194.68 & 207.65 \\
\hline & & (SD) & 125.07 & 122.42 & 124.52 & 139.22 & 130 & 127.37 & 126.88 \\
\hline & & Median & 182 & 217 & 198.5 & 183.5 & 194 & 186 & 195 \\
\hline & & $(\mathrm{IQR})$ & $105-272$ & $133-299$ & I20.5-292.5 & $10 \mid-286$ & $109-290$ & $98-280$ & $11 \mathrm{I}-286$ \\
\hline & \multirow[t]{5}{*}{ Female } & $\mathrm{N}$ & 282 & 196 & $13 \mid$ & 113 & 97 & 85 & 904 \\
\hline & & Mean & 203.8 & 221.29 & 199.18 & 198.02 & 186.55 & 191 & 203.15 \\
\hline & & (SD) & 124.88 & 117.72 & 134.13 & 124.75 & $|36.3|$ & 127.26 & 126.37 \\
\hline & & Median & 197 & 223.5 & 191 & 184 & 174 & 193 & 196 \\
\hline & & $(\mathrm{IQR})$ & $112-278$ & |47-284 & $91-275$ & $115-259$ & $88-265$ & $93-283$ & $104.5-275.5$ \\
\hline $\mathrm{p}$-value & Total & & \multicolumn{3}{|c|}{ Adulthood diagnosis } & \multicolumn{3}{|c|}{ Childhood diagnosis } & $<0.0001$ \\
\hline
\end{tabular}

Abbreviations: SD, standard deviation; IQR, interquartile range. 


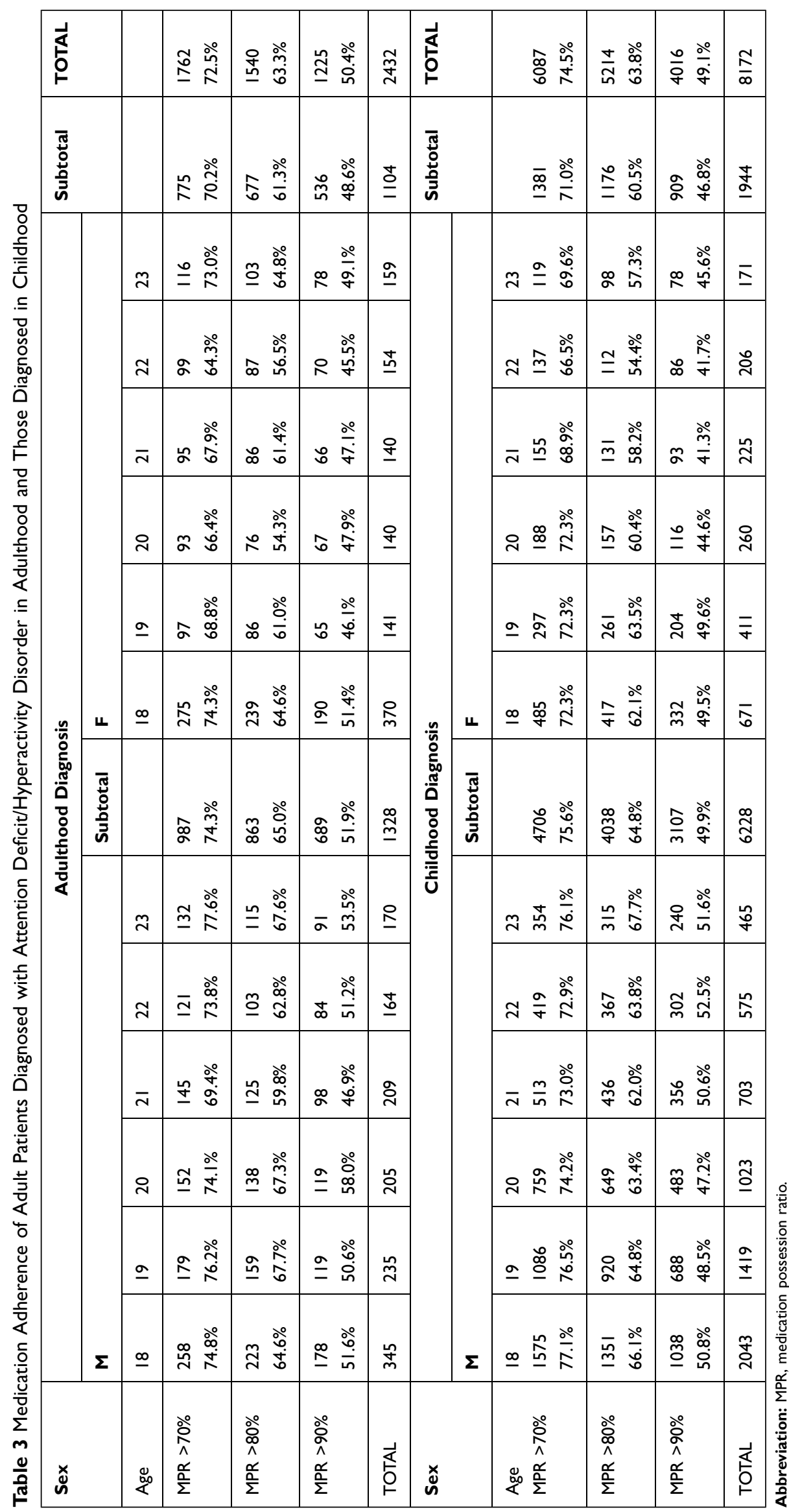


Medikinet (1.22\%). Most participants in the adulthood group were initially prescribed combination therapy (45.81\%), followed by Concerta $(28.33 \%)$, atomoxetine (11.06\%), Penid (10.07\%), bupropion (3.13\%), and Medikinet (1.03\%) (Figure 2).

\section{Persistence and Adherence}

The first 30-day gap occurred $136.95 \pm 124.91$ days and $206.47 \pm 126.74$ days after treatment initiation in the adulthood and childhood groups, respectively (Table 2). The timing of this gap was significantly different between groups $(\mathrm{p}<0.0001)$ (Table 2$)$. The proportions of medication persistence without a 30-day gap were $62.95 \%$ and $57.77 \%$ in the adulthood and childhood groups, respectively. An MPR of $80 \%$ was achieved in $63.3 \%$ and $63.8 \%$ of the adulthood and childhood groups, respectively (Table 3 and Figure 3).

\section{Associated Factors Affecting Adherence}

The results of the multivariate logistic regression analysis of adherence (MPR > $80 \%$ ) are presented in Table 4 . Treatment in a private clinic and initiation with combination medication were significantly associated with an MPR $>80 \%$ (odds ratios, 1.37 and 1.710 , respectively) in the adulthood group. In the regression analysis excluding nonpersistent participants, treatment in a private clinic and initial treatment with bupropion were significantly associated with an MPR $>80 \%$ in both groups (Table 4).

\section{Discussion}

This is the first study to compare the characteristics of adults with ADHD diagnosed in childhood or adolescence and those diagnosed in adulthood. Specifically, pharmacotherapy compliance was identified using NHIS claims data in terms of both persistence and adherence. This study

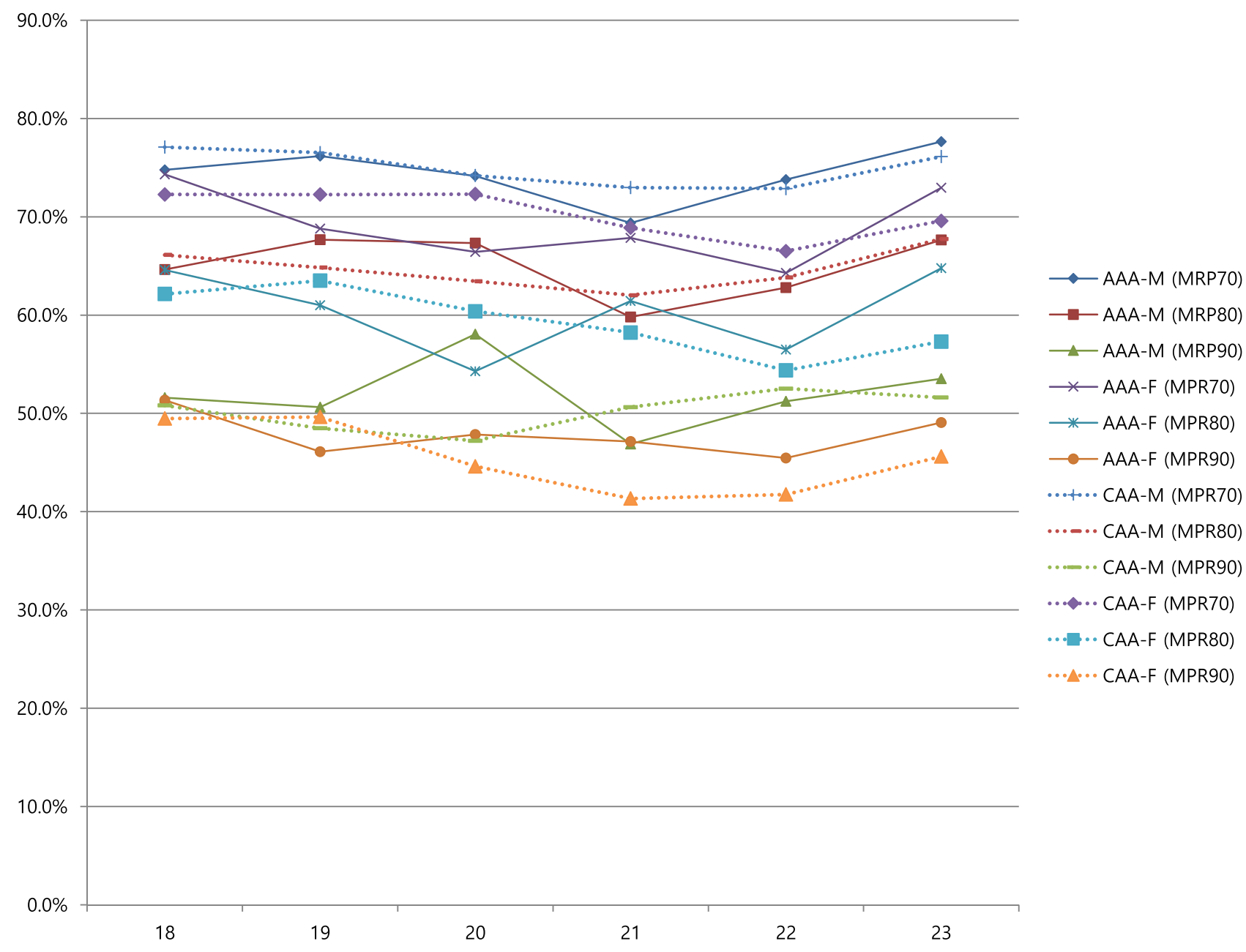

Figure 3 Medication adherence of adult patients diagnosed with ADHD in adulthood and those diagnosed in childhood.

Abbreviations: ADHD, attention deficit/hyperactivity disorder; AAA, Adulthood diagnosis of ADHD; CAA, Childhood or adolescent diagnosis of ADHD; M, male; F, female; MPR, medication possession ratio. 
Table 4 Multivariate Logistic Regression Analysis of Factors Associated with Medication Possession Ratio of at Least $80 \%$

\begin{tabular}{|c|c|c|c|c|c|c|c|c|c|}
\hline & & \multicolumn{8}{|c|}{ MPR $80 \%$} \\
\hline & & \multicolumn{4}{|c|}{ Adulthood Diagnosis } & \multicolumn{4}{|c|}{ Childhood Diagnosis } \\
\hline & & OR & $95 \% \mathrm{Cl}$ & & p-value & OR & $95 \% \mathrm{Cl}$ & & p-value \\
\hline \multirow[t]{2}{*}{ Sex } & $($ ref $=$ male $)$ & & & & & & & & \\
\hline & Female & 1.049 & 0.778 & 1.414 & 0.7531 & 0.907 & 0.703 & 1.171 & 0.4541 \\
\hline \multirow[t]{6}{*}{ Age } & $(r e f=18)$ & & & & & & & & \\
\hline & 19 & 0.916 & 0.58 & 1.448 & 0.708 & 0.889 & 0.668 & 1.184 & 0.4227 \\
\hline & 20 & 1.099 & 0.687 & 1.757 & 0.6944 & 0.839 & 0.6 & 1.173 & 0.3036 \\
\hline & 21 & 1.088 & 0.686 & 1.726 & 0.7199 & 1.182 & 0.838 & 1.667 & 0.3396 \\
\hline & 22 & 0.992 & 0.612 & 1.606 & 0.9731 & 1.03 & 0.7 & 1.515 & 0.8816 \\
\hline & 23 & 0.912 & 0.564 & 1.473 & 0.7054 & 0.912 & 0.596 & 1.395 & 0.6716 \\
\hline \multirow[t]{3}{*}{ Insurance } & (ref=Medical Aid) & & & & & & & & \\
\hline & NHI-employee's & 0.636 & 0.35 & 1.158 & 0.139 & 1.217 & 0.808 & 1.832 & 0.3474 \\
\hline & NHI-residence & 0.696 & 0.363 & 1.336 & 0.2763 & 1.545 & 0.985 & 2.424 & 0.0581 \\
\hline \multirow[t]{2}{*}{ Clinician's specialty } & (ref=psychiatry) & & & & & & & & \\
\hline & Others & 0.802 & 0.416 & 1.549 & 0.512 & 0.698 & 0.35 & 1.389 & 0.3054 \\
\hline \multirow[t]{2}{*}{ Treatment facility } & (ref= hospital) & & & & & & & & \\
\hline & Clinic & 1.602 & 1.1 & 2.332 & 0.0139 & 2.912 & 2.206 & 3.845 & $<0.0001$ \\
\hline \multirow[t]{2}{*}{ Region } & (ref= others) & & & & & & & & \\
\hline & Urban & 0.889 & 0.664 & 1.189 & 0.4263 & 0.892 & 0.724 & 1.101 & 0.2875 \\
\hline \multirow[t]{8}{*}{ Medication at initiation } & (ref=penid) & & & & & & & & \\
\hline & Medikinet & 1.142 & 0.237 & 5.514 & 0.8684 & 0.609 & 0.203 & 1.827 & 0.3765 \\
\hline & Bisphentin & 12.02 & 0.697 & 207.35 & 0.087 & 1.204 & 0.461 & 3.144 & 0.7049 \\
\hline & Concerta & 1.684 & 0.924 & 3.072 & 0.0889 & 0.687 & 0.436 & 1.084 & 0.1066 \\
\hline & Atomoxetine & 1.182 & 0.576 & 2.424 & 0.6487 & $\mathrm{I} .08 \mathrm{I}$ & 0.651 & 1.796 & 0.7628 \\
\hline & Bupropion & 2.513 & 1.008 & $6.26 \mathrm{I}$ & 0.048 & 2.365 & $1.24 \mid$ & 4.508 & 0.0089 \\
\hline & Clonidine & $<0.001$ & $<0.001$ & $>999.999$ & 0.9824 & $<0.001$ & $<0.001$ & $>999.999$ & 0.9766 \\
\hline & Combination & 2.041 & 1.15 & 3.622 & 0.0148 & 0.96 & 0.615 & 1.496 & 0.8553 \\
\hline
\end{tabular}

Abbreviations: MPR, medication possession ratio; OR, odds ratio; $\mathrm{Cl}$, confidence interval; $\mathrm{NHI}$, National Health Insurance.

has great clinical implications in that it presents the results on medication compliance of adult patients with ADHD after medication use was officially approved in Korea.

The main finding of the study is that certain demographic characteristics and the first used anti-ADHD medications for patients diagnosed at childhood or adulthood were identified. Male sex, Medical Aid insurance, and a diagnosis by a psychiatrist were more prominent in the childhood group than in the adulthood group. While combination or augmentation therapy was the most common initial treatment in the adulthood group, monotherapy with Concerta was the most common at initiation in the childhood group. The adulthood and childhood groups showed different characteristics. Our results may add evidence to suggest that adult-diagnosed ADHD may be a distinct entity from childhood ADHD. ${ }^{10,13}$ The compliance characteristics 
of each group were also identified. The childhood group had significantly better medication persistence than the adulthood group, but there was no difference in medication adherence (MPR). Third, the factors associated with adherence (MPR $>80 \%$ ) in each group were identified using multivariate logistic regression analysis.

When the conventional adherence standard of MPR $>80 \%$ was applied, ${ }^{14,15}$ treatment adherence was over $60 \%$ in both groups. In terms of persistence, over half of the participants had no 30-day gap in medications. These figures are similar to or better than previously published results. ${ }^{16,17}$ Zetterqvist et al found that the persistence of medication after 3 years was about $56 \%$ with Swedish national registry data. ${ }^{18}$

Interestingly, treatment in a private clinic and initial monotherapy with bupropion showed significant positive associations with adherence in our study, as both factors more than doubled the odds ratios. In particular, combination or augmentation therapy increased the odds ratio of adherence by 2.4 -fold in the adulthood group. Considering that bupropion is not the first-line treatment option for ADHD and that it is usually indicated for depression, this might suggest that comorbidities coexist in these patients. The association with treatment in a private clinic compared to hospitals can be interpreted as a benefit in accessibility. Based on our findings, it can be inferred that a thorough evaluation at the beginning of treatment and the utilization of private clinics might improve adherence.

There are clear limitations in using secondary databases. As we only used information collected from the NHIS, the effects of potentially significant factors such as educational level, socioeconomic status, intelligence, and disease severity or subtypes could not be determined. This issue can be solved by linking NHIS data with hospital medical records in the future. Second, it is difficult to generalize the results of this study to all adult age groups, as it is limited to only those in early adulthood. Third, unidentified individuals who did not use medical facilities covered by NHI could not be assessed.

Despite these limitations, this study has several strengths. The dataset used in this study is representative of the entirety of Korea and covers almost $97 \%$ of the total population. Although the target adult age range was somewhat narrow (18-23 years), each individual's claim data for at least a 10 -year period was screened and analyzed by strictly separating those diagnosed in adulthood from those diagnosed in childhood by limiting them to those with or without claims data of ADHD diagnosis and/or drug claims. In addition, we included almost all types of antiADHD medications currently in use in Korea.

A large-scale prospective cohort design that includes non-pharmacological treatment and tracks medical utilization patterns and pathways (dropout, remission, etc) is essential for future research.

\section{Acknowledgments}

This study was supported by a grant from the National Research Fund, Republic of Korea (NRF2019R1F1A1060615). We would like to thank Editage (www.editage.co.kr) for English language editing.

\section{Disclosure}

The authors report no conflicts of interest in this work.

\section{References}

1. Polanczyk GV, Willcutt EG, Salum GA, Kieling C, Rohde LA. ADHD prevalence estimates across three decades: an updated systematic review and meta-regression analysis. Int $J$ Epidemiol. 2014;43(2):434-442. doi:10.1093/ije/dyt261

2. Polanczyk G, de Lima MS, Horta BL, Biederman J, Rohde LA. The worldwide prevalence of ADHD: a systematic review and metaregression analysis. Am $J$ Psychiatry. 2007;164(6):942-948. doi:10.1176/ajp.2007.164.6.942

3. National Collaborating Centre for Mental Health. Attention Deficit Hyperactivity Disorder: Diagnosis and Management of ADHD in Children, Young People and Adults. Leicester (UK): National Collaborating Centre for Mental Health; 2009.

4. Murray DW, Arnold LE, Swanson J, et al. A clinical review of outcomes of the multimodal treatment study of children with attention-deficit/hyperactivity disorder (MTA). Curr Psychiatry Rep. 2008;10(5):424-431. doi:10.1007/s11920-008-0068-4

5. Wilens TE, Adamson J, Monuteaux MC, et al. Effect of prior stimulant treatment for attention-deficit/hyperactivity disorder on subsequent risk for cigarette smoking and alcohol and drug use disorders in adolescents. Arch Pediatr Adolesc Med. 2008;162(10):916-921. doi:10.1001/archpedi.162.10.916

6. Chien IC, Lin CH, Chou YJ, Chou P. Prevalence, incidence, and stimulant use of attention-deficit hyperactivity disorder in Taiwan, 1996-2005: a national population-based study. Soc Psychiatry Psychiatr Epidemiol. 2012;47(12):1885-1890. doi:10.1007/s00127012-0501-1

7. Hong M, Lee WH, Moon DS, Lee SM, Chung US, Bahn GH. A 36 month naturalistic retrospective study of clinic-treated youth with attention-deficit/hyperactivity disorder. $J$ Child Adolesc Psychopharmacol. 2014;24(6):341-346. doi:10.1089/cap.2013.0090

8. Hong M, Kim B, Hwang JW, et al. Naturalistic pharmacotherapy compliance among pediatric patients with attention deficit/hyperactivity disorder: a study based on three-year nationwide data. J Korean Med Sci. 2016;31(4):611-616. doi:10.3346/jkms.2016.31.4.611

9. Doernberg E, Hollander E. Neurodevelopmental Disorders (ASD and ADHD): DSM-5, ICD-10, and ICD-11. CNS Spectr. 2016;21 (4):295-299. doi:10.1017/S1092852916000262

10. Moffitt TE, Houts R, Asherson P, et al. Is adult ADHD a childhood-onset neurodevelopmental disorder? Evidence from a four-decade longitudinal cohort study. Am J Psychiatry. 2015;172 (10):967-977. doi:10.1176/appi.ajp.2015.14101266 
11. Agnew-Blais JC, Polanczyk GV, Danese A, Wertz J, Moffitt TE, Arseneault L. Evaluation of the persistence, remission, and emergence of attention-deficit/hyperactivity disorder in young adulthood. JAMA Psychiatr. 2016;73(7):713-720. doi:10.1001/jamapsychiatry.2016.0465

12. Cooper M, Hammerton G, Collishaw S, et al. Investigating late-onset ADHD: a population cohort investigation. $J$ Child Psychol Psychiatry. 2018;59(10):1105-1113. doi:10.1111/jcpp.12911

13. Lopez R, Micoulaud-Franchi JA, Galera C, Dauvilliers Y. Is adult-onset attention deficit/hyperactivity disorder frequent in clinical practice? Psychiatry Res. 2017;257:238-241. doi:10.1016/j.psychres. 2017.07.080

14. Peterson AM, Nau DP, Cramer JA, Benner J, Gwadry-Sridhar F, Nichol M. A checklist for medication compliance and persistence studies using retrospective databases. Value Health. 2007;10(1):3-12. doi:10.1111/j.1524-4733.2006.00139.x

15. Cramer JA, Roy A, Burrell A, et al. Medication compliance and persistence: terminology and definitions. Value Health. 2008;11 (1):44-47. doi:10.1111/j.1524-4733.2007.00213.x
16. Bejerot S, Ryden EM, Arlinde CM. Two-year outcome of treatment with central stimulant medication in adult attention-deficit/hyperactivity disorder: a prospective study. J Clin Psychiatry. 2010;71 (12):1590-1597. doi:10.4088/JCP.09m05168pur

17. van den Ban E, Souverein PC, Swaab $H$, van Engeland $H$, Egberts TC, Heerdink ER. Less discontinuation of ADHD drug use since the availability of long-acting ADHD medication in children, adolescents and adults under the age of 45 years in the Netherlands. Atten Defic Hyperact Disord. 2010;2(4):213-220. doi:10.1007/ s12402-010-0044-9

18. Zetterqvist J, Asherson P, Halldner L, Langstrom N, Larsson H. Stimulant and non-stimulant attention deficit/hyperactivity disorder drug use: total population study of trends and discontinuation patterns 2006-2009. Acta Psychiatr Scand. 2013;128(1):70-77. doi:10.1111/acps.12004

\section{Publish your work in this journal}

Neuropsychiatric Disease and Treatment is an international, peerreviewed journal of clinical therapeutics and pharmacology focusing on concise rapid reporting of clinical or pre-clinical studies on a range of neuropsychiatric and neurological disorders. This journal is indexed on PubMed Central, the 'PsycINFO' database and CAS, and is the official journal of The International Neuropsychiatric Association (INA). The manuscript management system is completely online and includes a very quick and fair peer-review system, which is all easy to use. Visit http://www.dovepress.com/testimonials.php to read real quotes from published authors. 